\title{
Apgar score and neonatal mortality in a hospital located in the southern area of São Paulo City, Brazil
}

\author{
Escore de Apgar e mortalidade neonatal em um hospital localizado \\ na zona sul do município de São Paulo
}

\author{
Tatiana Gandolfi de Oliveira ${ }^{1}$, Paula Vieira Freire², Flávia Thomé Moreira², Juliana da Silva Bemfeito de Moraes ${ }^{2}$, \\ Raquel Coris Arrelaro², Sarah Rossi² Viviane Alves Ricardi², Yara Juliano ${ }^{3}$, Neil Ferreira Novo², \\ José Ricardo Dias Bertagnon ${ }^{4}$
}

\begin{abstract}
Objective: To correlate the Apgar score, and neonatal mortality and its causes at a hospital located in the southern area of São Paulo City. Methods: A retrospective study performed by analysis of medical charts $(n=7,094)$ of all live newborns during the period of 2005 to 2009 , with data up to 28 days of life in reference to weight, Apgar score, survival and cause of mortality. Cases were analyzed by the $X^{2}$ test $(p<0.05)$. Results: In 7,094 births, there were 139 deaths, $58.3 \%$ during the first week, and $3.6 \%$ of them with Apgar $<4$ in the $1^{\text {st }}$ minute. A positive association was found between mortality and this variable, with significantly declining values up to $2,000 \mathrm{~g}$ in weight. In the group with weight $<1,000 \mathrm{~g}$, the association with Apgar $<4$ in the $1^{\text {st }}$ minute with mortality was three-fold greater than in the 1,000-1,500 $\mathrm{g}$ weight group, and 35 -fold greater than in the $\geq 3,000 \mathrm{~g}$ group. Among newborns with Apgar 8-10, the rate of mortality and low weight was two times greater than in those with weight $>2,499 \mathrm{~g}$. Fetal distress and prematurity were associated with early neonatal death; malformations and fetal distress to late mortality. The predictive value of death with Apgar $<4$ varied, according to weight, from $62.74 \%$ in the $<1,000 \mathrm{~g}$ group to $5.5 \%$, in the $>3,000 \mathrm{~g}$ group. Conclusions: The Apgar score proved linked to factors both epidemiological and related to attention given to the birth and neonatal mortality, and was associated with extremely low birth weight.
\end{abstract}

Keywords: Asphyxia neonatorum; Neonatal mortality (Public Health), Hospital, public

\section{RESUMO}

Objetivo: Correlacionar o escore de Apgar e a mortalidade neonatal e suas causas em um hospital localizado na zona Sul do município de
São Paulo. Métodos: Estudo retrospectivo por análise de prontuário $(\mathrm{n}=7.094)$, de todos os recém-nascidos vivos, no período de 2005 a 2009, com dados referentes até os 28 dias de vida, quanto a peso, escore de Apgar, sobrevida e causa de mortalidade. Os casos foram analisados pelo teste do $X^{2}(p<0,05)$. Resultados: Nos 7.094 nascimentos, houve 139 óbitos, 58,3\% na primeira semana, 3,6\% com Apgar $<4$ no $1^{\circ}$ minuto. Foi encontrada associação positiva entre mortalidade e essa variável, com valores decrescentes significantemente até o peso de $2.000 \mathrm{~g}$. No grupo de peso $<1.000 \mathrm{~g}$, a associação do Apgar $<4$ no $1^{\circ}$ minuto com mortalidade foi três vezes maior do que no grupo 1.000 a $1.500 \mathrm{~g} \mathrm{e} 35$ vezes maior do que no grupo $\geq 3.000 \mathrm{~g}$. Entre os recém-nascidos com Apgar de 8 a 10, a mortalidade entre baixo peso foi duas vezes maior do que nos de peso $>2.499 \mathrm{~g} .0$ sofrimento fetal e a prematuridade se associaram a óbito neonatal precoce; malformações e 0 sofrimento fetal à mortalidade tardia. 0 valor preditivo de morrer quando o Apgar $<4$ variou, conforme o peso, entre $62,74 \%$ no grupo $<1.000 \mathrm{~g}$ a $5,5 \%$ no grupo $>3.000 \mathrm{~g}$. Conclusões: 0 escore de Apgar se mostrou ligado a fatores epidemiológicos e de atenção ao parto, à mortalidade neonatal e se associou a extremo baixo peso.

Descritores: Asfixia neonatal; Mortalidade neonatal; Hospitais públicos

\section{INTRODUCTION}

Perinatal mortality, which encompasses fetal deaths and early neonatal deaths, is an indicator of maternal-infant health, reflecting both the conditions of reproductive health, which are linked to socioeconomic factors, and

\footnotetext{
Study carried out at Hospital Estadual do Grajaú - HGG, São Paulo (SP), Brazil.

${ }^{1}$ Medical School, Universidade de Santo Amaro - UNISA, São Paulo (SP), Brazil.

${ }^{2}$ Medical Course, Medical School, Universidade de Santo Amaro - UNISA, São Paulo (SP), Brazil.

${ }^{3}$ Department of Collective Health Department, Medical School, Universidade de Santo Amaro - UNISA, São Paulo (SP), Brazil.

${ }^{4}$ Department of Pediatrics, Medical School, Universidade de Santo Amaro, São Paulo (SP), Brazil.

Correspondence: Tatiana Gandolfi de Oliveira - Rua Edson, 389 - Campo Belo - Zip code: 04618-031 - São Paulo (SP), Brazil - Phone: (11) 5042-4078 - E-mail: tatianagandolfi@uol.com.br

Received on: Nov 11, 2010 - Accepted on: Jan 11, 2012
}

Conflict of interest: None 
the quality of perinatal care - prenatal, delivery, and neonatal ${ }^{(1)}$.

The clinical evaluation of the newborn (NB) was proposed by Virginia Apgar in 1953 and 1958, and has been very useful in assessing the need for resuscitation of newborns, when applied at the $1^{\text {st }}$ minute of life, and again at $5^{\text {th }}$ minute ${ }^{(2)}$.

Since it is the only form of evaluation in developing countries, where laboratory tests may not be available, the low cost of the Apgar score is useful in identifying children who need additional care, even in the absence of laboratory data ${ }^{(3)}$.

There is a consensus that an Apgar score of 7-10 means that the child is healthy and that it will probably not have future problems ${ }^{(4)}$. When the score is $<7$, it is a sign of alert for special attention. There are different levels of low Apgar score, according to pathophysiologic changes. Additionally, it partially depends on the maturity of the fetus. Maternal conditions, such as medications, may also influence the score and finally, the very conditions of the NB influence the assessment, for example, neuromuscular or cerebral malformations and respiratory conditions ${ }^{(3)}$.

Apgar scores, birth weight, and gestational age are highly related to survival and, in combination, are a measure of the NB well-being, of the success of the resuscitation, of the size and maturity of the $\mathrm{NB}^{(5)}$.

Annually, there are about 7.6 million perinatal deaths, $98 \%$ of which in developing countries ${ }^{(6)}$. About $57 \%$ of these are represented by fetal deaths, which have shown a very slow decline. Compared to natimortality, neonatal mortality has shown a greater reduction, although not as intense as what is seen in developed countries where mortality has been reduced for all gestational age groups and birth weight ${ }^{(7-9)}$.

Determinants of infant mortality have been studied exclusively by means of epidemiological investigations, and one significant conclusion is that in 1990, there was continuous mortality among NB and children, most of them in developing countries ${ }^{(10)}$.

The mean drop in infant mortality during the 1990s was estimated most noticeably at the ages of two to four years, with a $10.5 \%$ decrease, and for one-year-old children there was a reduction by $4 \%$. As to neonatal and postneonatal mortality, rates fell less significantly, 3.0 and $2.5 \%$, respectively ${ }^{(10)}$. As a result, there was an increase in the proportion of deaths in children during the neonatal period, which today represents, worldwide, two thirds of the deaths in children under one year of age and almost four tenths of the total number of deaths in children aged under 5 years ${ }^{(11)}$.
Infant mortality rates for the city of São Paulo fell from $12.4 \%$ in 2007 , to $11.9 \%$, in 2009 . In the region of Capela do Socorro, where this project was carried out, it fell from $17.1 \%$ to $13.0 \%{ }^{(12)}$. Infant mortality rates reflect primarily the load of neonatal mortality in the country. A considerable portion of these deaths were due to avoidable causes, which means that interventions could have been effective. Nevertheless, the reduction in neonatal mortality is hindered by the complex and close relation between biological and social factors, and by covering and quality of healthcare services during the prenatal, birth, and neonatal periods ${ }^{(12)}$.

Perinatal asphyxia appears as one of the major causes of neonatal mortality and is linked to epidemiological factors, care provided during delivery, and an association with extremely low birth weight. However, its evaluation still lacks markers that are practical, precise, and immediate for the neonatologist, especially in situations in which technological resources are scarce. It is noteworthy that measuring perinatal risk factors requires knowledge of the natural history of complications of pregnancy and delivery, as well as an epidemiological study of each event defined relative to the local site. Also important is the fact that prenatal care currently has extremely broad goals, and besides its psychological, education, and social purposes, it is concerned primarily with the identification of the high-risk pregnancy, which requires and even more personalized and specialized management. The establishment of a gestational risk hierarchy, referral of high-risk pregnant women to tertiary care centers, restriction of smoking during gestation, diagnosis of intercurrent pathologies, early hospitalization, and correct and discerning use of advanced technologies are instruments of extreme importance for the reduction of maternal and perinatal mortality ${ }^{(13)}$.

\section{OBJECTIVE}

To correlate the Apgar score with neonatal mortality and its causes at a hospital located in the southern zone of the municipality of São Paulo.

\section{METHODS}

Retrospective study, based on analysis of data from the System of Information on Liveborns (SINASC) and of medical charts of NB up to 28 days as to the Apgar score during the $1^{\text {st }}$ and $5^{\text {th }}$ minutes, at the Hospital Estadual do Grajaú (HEG) located in the region of the Capela do Socorro neighborhood, southern zone of the city of São Paulo (SP). 
The HEG cares for a population situated below the line of poverty that is in need of better medical resources. It is a teaching hospital, with interns and residents, training for nurses and various other healthcare professionals, with personnel and material resources recommended for good obstetric and neonatal care. The pregnant women seen there include a large number of adolescents, women who have no prenatal accompaniment, with a high frequency of prematurity and low-weight NBs.

This analysis included all the live NB of that hospital during the years 2005 to $2009(n=7,126)$ and excluded the cases in which there was no recording of weight, Apgar score or possibility of evaluating the cause related to death $(n=32)$; thus, 7,094 records were analyzed. Data was obtained by means of the SINASC databank ${ }^{(13)}$ and, in the case of the deaths $(n=136)$, by analysis of clinical charts of the neonatal unit of the hospital, with a survey of variables relative to weight, 1 st and 5th minute Apgar scores, and in cases of death, weight, time of survival, and causes related to mortality.

Apgar scores in the SINASC databank were groups according to number of points ( $0-3 ; 4-7$; and 8 or more). In this way, it was not possible to analyze the data of the neonatal deaths to compare them with those of live NB with Apgar scores $\leq 6$ in the $5^{\text {th }}$ minute of life, as is recommended by literature. The Apgar scores were compared in the groups of survivors; in the group of deaths, by $\chi^{2}(\mathrm{p}<0.05)$. The proportionate mortality ratio (PMR) by birth weight during the period studied, in the different groups, classified as per the Apgar score: from 0-3, 4-7, and 8-10, as presented in SINASC. The early and late neonatal mortality was calculated for these same groups for different Apgar scores, for each group of weight, for the $1^{\text {st }}$ and $5^{\text {th }}$ minutes of life. This risk was calculated by the division of deaths with Apgar scores $<4$ and 4-7 in each weight group, divided by the number of deaths in these weight groups, multiplied by 1000. The causes of mortality were selected and grouped according to the basic cause into four categories: "fetal distress," "prematurity," "infection", and "malformations." Fetal distress was considered when this was determined by the clinical picture, not taking into consideration the value of Apgar score. In this group were the NB who presented with signs of fetal distress, such as cardiac deceleration, centralization, presence of meconium in the amniotic fluid in cases of vertex presentation, or delay in manifestations of vitality, requiring assisted ventilation, in the absence of suspicions of infection, respiratory distress syndrome, and malformations. Prematurity was considered when the gestational age was below 27 weeks and other causes were excluded.
Infection was recorded when the clinical and laboratorial pictures were suggestive of this. Malformations were considered when the clinical progress showed this cause as determinant of death. The relation of the basic cause of death with a 1-minute Apgar score $<4$ was made using the $\chi$ method for $\mathrm{p}<0.005$.

The project was approved by the Research Ethics Committee of the institution, under Number 002/2010 dated $24^{\text {th }}$ of february, 2010.

\section{RESULTS}

Among the 7,094 births, there were 136 deaths, 58.3\% during the first week, $3.6 \%$ of NB with an Apgar score $<4$ during the $1^{\text {st }}$ minute, with a positive association between mortality and this variable, showing significantly decreasing values until the weight of $2,000 \mathrm{~g}$.

In the group of weight $<1,000 \mathrm{~g}$, the association between the variable " 1 -minute Apgar $<4$ " and mortality was three-fold greater than in the 1,000-1,500 g group, and 35 -fold greater than in the $\geq 3,000 \mathrm{~g}$ group. Among the NB with Apgar 8-10, mortality among those with low weight was two times greater than in those $>2,499 \mathrm{~g}$. The association between weight and mortality had $\chi^{2}$ of 1,252.24 ( $\mathrm{p}<0.0001$ ), and between "1-minute Apgar $<4$ " and mortality, it was $626.46(\mathrm{p}<0.0001)$.

On table 1, the PMR per group of weight for the values of Apgar score is shown. It is noted that the coefficients decrease as the value of Apgar increases. It is also noted that, for the same group of Apgar scores, there is a decline in the ratio as the NB weight increases. Even in the weight $<1,000 \mathrm{~g}$ group, in which mortality is very high, there is a decrease in mortality rates as the value of Apgar increases. The predictive value of death when Apgar score was < 4, varied according to weight, between $62.74 \%$ in the group of weight $<1,000 \mathrm{~g}$ and $5.5 \%$ in the group of weight $\geq 3,000 \mathrm{~g}$.

It can be noted that in the Apgar 0-3 group, with exception of the $<1,000 \mathrm{~g}$ group, the coefficients prove to be similar ( $p>0.05$ among the groups of weight of 1,000 to 3,500g) and the PMR were significantly greater than in the other groups $(\mathrm{p}<0.0004)$, with the exception of the weight group of $<1,500 \mathrm{~g}$, in which mortality occurred independently from Apgar.

On table 2, it was observed that early neonatal mortality proved greater than late neonatal mortality in the three groups of smallest weight, with a tendency to equalize in the NB that weighed over $2,000 \mathrm{~g}$. In observing NBs with Apgar < 4, in all groups of weight, early mortality was greater than was late mortality. The weight group $<1,000 \mathrm{~g}$ and with Apgar $<4$ showed a mortality significantly greater than that of other groups 
Table 1. Newborns: neonatal mortality proportional to weight and Apgar score

\begin{tabular}{|c|c|c|c|c|c|c|c|c|}
\hline \multirow[b]{2}{*}{ Weight } & \multicolumn{2}{|c|}{ Apgar 0-3 } & \multicolumn{2}{|c|}{ Apgar 4-7 } & \multicolumn{2}{|c|}{ Apgar 8-10 } & \multicolumn{2}{|c|}{ Total } \\
\hline & $\begin{array}{c}\text { Liveborn } \\
\mathbf{n}\end{array}$ & PMR\% & $\begin{array}{c}\text { Liveborn } \\
\mathbf{n}\end{array}$ & PMR\% & $\begin{array}{c}\text { Liveborn } \\
\mathbf{n}\end{array}$ & PMR\% & $\begin{array}{c}\text { Liveborn } \\
\mathbf{n}\end{array}$ & PMR\% \\
\hline $500-999$ & 42 & 785.7 & 44 & 522.7 & 14 & 500.0 & 100 & 630.0 \\
\hline $1,000-1,499$ & 24 & 208.3 & 40 & 150.0 & 36 & 166.6 & 100 & 170.0 \\
\hline $1,500-1,999$ & 28 & 285.0 & 62 & 80.6 & 128 & 156.4 & 218 & 68.8 \\
\hline $2,000-2,499$ & 33 & 182.0 & 115 & 17.4 & 499 & 4.00 & 647 & 15.5 \\
\hline $2,500-2,999$ & 52 & 38.4 & 213 & 32.9 & 1,745 & 2.86 & 2,010 & 6.96 \\
\hline $3,000-3,499$ & 61 & 132.1 & 259 & 7.77 & 2,434 & 2.05 & 2,754 & 5.44 \\
\hline 3,500 ou + & 33 & 60.6 & 169 & 0.0 & 1,063 & 4.7 & 1,265 & 5.33 \\
\hline Total & 273 & 234.4 & 902 & 49.9 & 5,919 & 5.40 & 7,094 & 19.87 \\
\hline
\end{tabular}

$X^{2}=1,252.24(p<0.0001)$ for weight and mortality and $626.46(p<0.0001)$ for Apgar $<4$ and mortality.

PMR: proportionate mortality ratio.

Table 2. Newborns: late neonatal mortality, proportional to weight and Apgar score

\begin{tabular}{|c|c|c|c|c|c|c|c|c|}
\hline \multirow[b]{2}{*}{ Weight } & \multicolumn{2}{|c|}{ Apgar 0-3 } & \multicolumn{2}{|c|}{ Apgar 4-7 } & \multicolumn{2}{|c|}{ Apgar 8-10 } & \multicolumn{2}{|c|}{ Total } \\
\hline & $\begin{array}{c}\text { Liveborn } \\
\mathbf{n}\end{array}$ & Late PMR\% & $\begin{array}{c}\text { Liveborn } \\
\mathbf{n}\end{array}$ & Late PMR\% & $\begin{array}{c}\text { Liveborn } \\
\mathbf{n}\end{array}$ & Late PMR\% & $\begin{array}{c}\text { Liveborn } \\
\mathbf{n}\end{array}$ & Late PMR\% \\
\hline $500-999$ & 42 & 142.90 & 44 & 90.90 & 14 & 214.30 & 100 & 130.00 \\
\hline $1,000-1,499$ & 24 & 41.70 & 40 & 100.00 & 36 & 138.90 & 100 & 100.00 \\
\hline $1,500-1,999$ & 28 & 71.40 & 62 & 48.40 & 128 & 4.00 & 218 & 32.10 \\
\hline $2,000-2,499$ & 33 & 60.60 & 115 & 8.70 & 499 & 4.00 & 647 & 7.73 \\
\hline $2,500-2,999$ & 52 & 0.00 & 213 & 23.50 & 1,745 & 1.71 & 2,010 & 3.97 \\
\hline $3,000-3,499$ & 61 & 49.20 & 259 & 3.86 & 2,434 & 1.64 & 2,754 & 2.90 \\
\hline 3,500 ou + & 33 & 60.60 & 169 & 0.00 & 1,063 & 2.82 & 1,265 & 3.95 \\
\hline Total & 273 & 54.94 & 902 & 21.10 & 5,919 & 3.71 & 7,094 & 7.89 \\
\hline
\end{tabular}

PMR: proportionate mortality ratio

( $p<0.003)$, but, according to the partition of the $x^{2}$ test, it was noted that in all weight groups, mortality increased greater as the Apgar decreased $(\mathrm{p}<0.0004)$.

In observing the NB group with Apgar 4-7 as well as the group with Apgar 8-10, we noted that only for the NBs with weights $<1,000 \mathrm{~g}$ was early mortality greater than late mortality.

On table 3, it can be seen that the PMR in the 1st and 5 th minutes showed a trend to decrease as the NB weight increased. In the category of $3,000 \mathrm{~g}$ or more, mortality increased in NB with Apgar of 0-3 in 1 and 5 minutes, relative to the NB with weights between 2,500 and 2,999 $\mathrm{g}$ and yet, mortality increased for those with Apgar scores of 4-7relative to NB with weights between $1,500 \mathrm{~g}$ and $2,999 \mathrm{~g}$.

Tables 4,5 , and 6 show relations between the selected causes of death with characteristics of the NB: the mortality was associated with very-low-weight NB, with fetal distress, infection, and prematurity. Malformation was related to weights $>1,500 \mathrm{~g}$. Fetal distress and prematurity were associated with early mortality and infection, and malformation, with late mortality. Fetal distress and prematurity were associated with Apgar $<4$ and infection, and malformation with Apgar $\geq 4$. Among the NB with fetal distress, among those with 5-minute Apgar $<7$, there was an association both with early and late mortality, depending on the weight group. Malformations appeared as the most frequent cause of late mortality and most frequently among NB with greater weight. There was no difference as to infection as predominant cause of early or late death.

Table 7 shows the relation between early mortality and selected causes of mortality, and of late mortality and selected causes of mortality, in NB with 5-minute Apgar scores of $\leq 6$ or $>6$.

When early mortality was evaluated, a significant difference was noted between the frequencies of deaths in the various classes, when separated by the 5-minute Apgar result.

The greatest associations of deaths with 5-minute Apgar $\leq 6$ were with malformation and fetal distress, more than with infection and prematurity, despite 
Table 3. Association between causes of death and 1-minute Apgar score $\leq 3$ and $>3$

\begin{tabular}{|c|c|c|c|c|}
\hline Cause of death & 1-minute Apgar $\leq 3$ & 1-minute Apgar > 3 & Total & Proportion of yes $(\%)$ \\
\hline Anoxia & 19 & 12 & 31 & 68.62 \\
\hline Infection & 12 & 34 & 46 & 26.08 \\
\hline Malformation not compatible with life & 7 & 16 & 23 & 33.33 \\
\hline Prematurity & 18 & 18 & 36 & 52.94 \\
\hline Total & 56 & 80 & 136 & 43.07 \\
\hline
\end{tabular}

$X^{2}=8.59 ; p<0.0333$

Table 4. Association between causes of early neonatal death and 5-minute Apgar $\leq 6$ and $>6$

\begin{tabular}{|c|c|c|c|c|}
\hline Cause of death & 5-minute Apgar $\leq 6$ & 5-minute Apgar > 6 & Total & Proportion of yes $(\%)$ \\
\hline Anoxia & 18 & 9 & 27 & 65.38 \\
\hline Infection & 5 & 13 & 18 & 22.22 \\
\hline Malformation not compatible with life & 7 & 3 & 10 & 66.6 \\
\hline Prematurity & 8 & 15 & 23 & 31.81 \\
\hline Total & 38 & 40 & 78 & 45.33 \\
\hline
\end{tabular}

$X^{2}=10.89 ; p<0.0123$

Table 5. Association between causes of late neonatal death and 5-minute Apgar $\leq 6$ and $>6$

\begin{tabular}{|c|c|c|c|c|}
\hline Cause of death & 5-minute Apgar $\leq 6$ & 5-minute Apgar > 6 & Total & Proportion of yes (\%) \\
\hline Anoxia & 3 & 3 & 6 & 50.00 \\
\hline Infection & 4 & 21 & 25 & 16.00 \\
\hline Malformation not compatible with life & 2 & 12 & 14 & 14.28 \\
\hline Prematurity & 3 & 10 & 13 & 27.28 \\
\hline Total & 12 & 46 & 58 & 29.09 \\
\hline
\end{tabular}

$X^{2}=6.264: p=0.0996($ NS)

Table 6. Association between causes of death and survival time

\begin{tabular}{|c|c|c|c|c|}
\hline Cause of death & Early neonatal death & Late neonatal death & Total & Proportion of yes $(\%)$ \\
\hline Anoxia & 24 & 5 & 29 & 82.75 \\
\hline Infection & 20 & 30 & 60 & 39.13 \\
\hline Malformation not compatible with life & 9 & 13 & 22 & 42.85 \\
\hline Prematurity & 25 & 10 & 35 & 73.52 \\
\hline Total & 78 & 58 & 136 & 58.46 \\
\hline
\end{tabular}

$X^{2}=18.97 ; p=0.0003$

Table 7. Association between causes of early neonatal death and 5-minute Apgar $\leq 6$ and $>6$ and late neonatal death and 5 -minute Apgar $\leq 6$ and $>6$

\begin{tabular}{|c|c|c|c|c|c|c|c|c|}
\hline \multirow{2}{*}{$\begin{array}{l}\text { Selected causes } \\
\text { of death }\end{array}$} & \multicolumn{4}{|c|}{ Early neonatal mortality } & \multicolumn{4}{|c|}{ Late neonatal mortality } \\
\hline & $\begin{array}{c}\text { 5-minute } \\
\text { Apgar } \leq 6\end{array}$ & $\begin{array}{c}\text { 5-minute } \\
\text { Apgar }>6\end{array}$ & Total & $\begin{array}{c}\text { Proportion of } \\
\text { yes }(\%)\end{array}$ & $\begin{array}{c}\text { 5-minute } \\
\text { Apgar } \leq 6\end{array}$ & $\begin{array}{c}\text { 5-minute } \\
\text { Apgar > } 6\end{array}$ & Total & $\begin{array}{c}\text { Proportion of } \\
\text { yes (\%) }\end{array}$ \\
\hline Fetal distress & 16 & 8 & 24 & 66.6 & 3 & 2 & 5 & 60.00 \\
\hline Infection & 5 & 13 & 18 & 25.0 & 5 & 23 & 28 & 16.00 \\
\hline Malformation & 6 & 3 & 9 & 66.6 & 2 & 10 & 12 & 14.28 \\
\hline Prematurity & 8 & 17 & 25 & 31.81 & 3 & 6 & 9 & 27.28 \\
\hline Total & 35 & 41 & 76 & 45.33 & 13 & 41 & 54 & 29.09 \\
\hline
\end{tabular}

Early: $\chi^{2}=10.89 ; \chi^{2}$ critical $=7.81 ;$ late: $\chi^{2}=6.264 ; \chi^{2}$ critical $=7.81$. 
the greater frequency of prematurity, fetal distress, and infection. Mortality due to malformation had the greatest frequency among NB with 5-minute Apgar $>6$.

There was no significant difference between the frequencies of death in the various classes, separated by the 5-minute Apgar, among the NB who had late mortality.

The greatest associations between death and Apgar $\leq 6$ were with fetal distress, but this association was not significant.

\section{DISCUSSION}

Neonatal mortality is related to several variables. The smaller the birth weight, the greater the mortality ${ }^{(1-14)}$. Perinatal asphyxia is also related to mortality ${ }^{(3-6)}$. The Apgar score is the most well-known and earliest form of measuring neonatal asphyxia ${ }^{(4-5)}$. For a long time, a score of 0-3 during the $1^{\text {st }}$ minute of life determined respiratory ventilation with the most appropriate resuscitation maneuver. New knowledge, such as the determination of the blood $\mathrm{pH}$ of the fetus, among others, modified this concept and the score of 6 or less in the $5^{\text {th }}$ minute became the most important reference point in the diagnosis and prognosis of asphyxia, along with the proposal of not waiting for the one-minute score to initiate resuscitation maneuvers ${ }^{(15)}$. In spite of this, the one-minute score still seems to have importance in the prognosis of mortality ${ }^{(4)}$.

Perinatal asphyxia leads to significant damage in all systems of the fetus and NB. The oxygen supply through the placenta increases with the end of gestation, in parallel to the greater needs of the fetus ${ }^{(3-15,16)}$. Neonatal asphyxia is closely related to early neonatal mortality, but the perfecting of new techniques in neonatal care, decreasing mortality, and also prolonging survival, is shifting mortality related to this cause to later periods, and death may come as late neonatal or postneonatal death $^{(6,7)}$. The Apgar score, despite not being an indicator for resuscitation maneuvers, could still be the prognostic marker of mortality secondary to perinatal asphyxia.

Carvalho et al. ${ }^{(14)}$, using bivariate analysis of sample of 4,629 liveborns and 213 deaths, verified a statistically significant association with neonatal death in groups born with gestational ages up to 36 weeks. In the present study, the findings were similar, demonstrating the relation of mortality with smaller weights. The damage caused by anoxia in the very-low-weight NB fragile body leads to cell damage, renal insufficiency, peri- and intraventricular hemorrhage, patent ductus arteriosus, increased capillary permeability, and maintenance of fetal pulmonary hypertension, among others, resulting in a chain of irreversible organic insufficiency that culminates in death.

Generally death occurs during the first week, and for most, within the first 24 hours. In this way, it is expected that a population with a higher frequency of NBs with extremely low weight and asphyxia present with high early neonatal mortality rates ${ }^{(3)}$. Prematurity is associated with birth weight and, among those low-weight NB, there are the premature and the malnourished, who are children at risk of death, even in the absence of asphyxia, which is in agreement with the findings of this present study. The premature NB may be born vigorous and with an adequate Apgar score, but manifests worsening of its clinical condition and later dies. This fact may be explained perhaps because the association of mortality occurred more intensely with the low birth weight than with the low 1-minute Apgar scores, as was found in this study, considering the significant association between the low Apgar and low weight with mortality. Although an Apgar $>3$ does not mean absence of anoxia, its association with mortality shows that it identifies risk of early death in all classes of birth weight ${ }^{(4)}$.

Considering that, as a rule, a low Apgar score may reflect fetal distress, the findings of this study are clear. As low weight is associated with the consequences of fetal distress, the NB compensation mechanisms are acutely compromised, with death in a shorter time. The lower weight NB, however, has better recovery mechanisms, despite the damage that becomes irreversible due to lesions, especially cerebral and cardiac, provoked by the asphyxia. This fact would be related to late neonatal death $^{(16)}$.

In most cases, NB with Apgar $\geq 4$ do not present with higher rates of early than late mortality, with exception of those with extremely low weights. Such a group, possibly, died due to other causes, not influenced by the deleterious effect of asphyxia, suggesting the Apgar score really can foresee greater life risk in all groups of NB weight.

There was an association between weight and gestational age, and very likely, among the NB with weights of 3,000 g or more are the full-term NBs. At the end of gestation, there is a greater supply of $\mathrm{O}_{2}$ to the fetus that is more susceptible to the lack of $\mathrm{O}_{2}$. In this way, the lack of $\mathrm{O}_{2}$ becomes more damaging to the cell, especially brain cells, leading to irreversible harm and culminating in death ${ }^{(16)}$. In this group are also the cases of meconium aspiration syndromes, a disorder that affects NB with more than 35 weeks gestation and, thus, with greater weights. 
As to the causes of mortality, the trend of a statistical association between the causes of death and 1-minute Apgar $<4$ becomes more evident. This association, however, did not prove significant, probably due to the small number of cases for each variable.

Hospital infections may manifest throughout the entire period of NB hospitalization. The NB with greatest survival have the greatest chances of acquiring hospital infection, especially the premature NB, with a greater need for invasive procedures ${ }^{(7)}$. As has already been stated, premature NB have less adaptive capacity to attain equilibrium during an event of asphyxia, justifying that the addition of prematurity to Apgar 0-3 is related to greater mortality ${ }^{(16)}$.

In most cases, malformations are not associated with very low weight or with fetal distress. Hence, any NB with a malformation incompatible with life will die regardless of its weight and Apgar score. These were identified as more frequent causes of late death than of early death in the present study. This fact probably occurs for two main reasons: there is some adaptation in the malformed NB, primarily as to cardiac malformations and hematologic disorders, which would benefit from the extrauterine period of adaptation. After this period is complete, the imbalances resulting from the malformation are felt more irreversibly. Some malformations require ventilator support and other invasive procedures that can prolong life for a longer period, which does not happen with NB with other disorders studied ${ }^{(16)}$. The 5-minute Apgar score below 7 may be considered an indicator of asphyxia and thus, would measure risk of death. The high frequency of deaths by asphyxia and malformations among NB with 5 -minute Apgar $<7$ showed a significant association with early mortality, although the greater number of deaths due to malformations occurred after seven days.

In the present study fetal distress and prematurity were associated with early neonatal death. The frequencies of the various disorders reported as causes of death were differentiated by the 5-minute Apgar score $>$ or $<6$ when early neonatal mortality was analyzed.

Such an association did not prove significant when studying late mortality and Apgar, likely because in this situation the NB with severe asphyxia, associated with prematurity and malformations, had an earlier death.

\section{CONCLUSION}

For the population studied, the 1-minute and 5-minute Apgar scores were good tools for predicting mortality.

This study has limitations. The fact of being a retrospective study, based on information from a noninstitutional database, albeit official and the evaluation of cases of death and their causes made based on hospital medical charts, may have constituted a bias factor. However, these data reflect a reality which is very common in our hospitals, which can be interpreted as a diagnosis of the situation, which might eventually be useful in similar institutions.

\section{REFERENCES}

1. Jackson DJ, Lang JM, Ganiats TG. Epidemiological issues in perinatal outcomes research. Paediatr Perinat Epidemiol. 1999;13(4):392-404.

2. APGAR V. A proposal for a new method of evaluation of the newborn infant. Curr Res Anesth Analg. 1953;32(4):260-7.

3. Cunha AA, Fernandes DS, Melo PF, Guedes MH. Fatores associados à asfixia perinatal. Rev Bras Ginecol Obstet. 2004;26(10):799-805.

4. Casy BM, Mclntire DD, Leveno KJ. The continuing value of the Apgar score for the assessment of newborn infants. N Engl J Med. 2001;344(7):467-71.

5. De Hart MP. Racial differences in Apgar scores and mortality and morbidity in low birthweight infants [dissertation]. Baltimore (MD): Johns Hopkins University; 1994.

6. World Health Organization. Perinatal mortality. A listing of available information. Geneva: World Health Organization; 1996.

7. Leal MC, Szwarcwald CL. Evolução da mortalidade neonatal no Estado do Rio de Janeiro, Brasil, de 1979 a 1993. 1 - Análise por grupo etário segundo região de residência. Rev Saúde Pública. 1996;30(5):403-12.

8. Hein HA, Lofgren MA. The changing pattern of neonatal mortality in a regionalized system of perinatal care: a current update. Pediatrics. 1999; 104(5 Pt 1):1064-9.

9. Joseph KS, Kramer MS, Allen AC, Cyr M, Fair M, Ohlsson A, et al. Gestational age- and birthweight specific declines in infant mortality in Canada, 1985-94. Fetal and Infant Health Study Group of the Canadian Perinatal Surveillance System. Paediatr Perinat Epidemiol. 2000;14(4):332-9.

10. Rutstein SO. Factors associated with trends in infant and child mortality in developing countries during the 1990s. Bull World Health Organ. 2000; 78(10):1256-70.

11. Moss W, Darmstadt GL, Marsh DR, Black RE, Santosham M. Research priorities for the reduction of perinatal and neonatal morbidity and mortality in developing countries. J Perinatol. 2002;22(7):484-95.

12. Simões CCS. Perfis de saúde e de mortalidade no Brasil: uma análise de seus condicionantes em grupos populacionais específicos. Brasília, DF: Organização Pan-Americana da Saúde/Organização Mundial da Saúde; 2002.

13. SINASC- Sistema de informação de nascidos vivos [Internet]. São Paulo; 2009. [citado 2010 Mar 20]. Disponível em: http://www.datasus.gov.br/ catalogo/sinasc.htm

14. Carvalho PI, Pereira PM, Frias PG, Vidal AS, Figueiroa JN. Fatores de risco para mortalidade neonatal em coorte hospitalar de nascidos vivos. Epidemiol Serv Saúde. 2007;6(3):185-94.

15. American Academy of Pediatrics, Committee on Fetus and Newborn; American College of Obstetrician and Gynecologists and Committee on Obstetric Practice. The Apgar Score. Pediatrics. 2006;117(4):1444.

16. Shah GS, Singh R, Das BK. Outcome of newborns with birth asphyxia. JNMA J Nepal Med Assoc. 2005;44(158):44-6. 